\title{
INVESTIGATION OF PHYSICAL AND SENSORY PROPERTIES OF ETHIOPIAN SPECIALTY DRY PROCESSED GREEN COFFEE BEANS
}

\author{
- Research paper - \\ Yishak WORKU WONDIMKUN ${ }^{1 *}$, Shimelis ADMASSU EMIRE*, Tarekegn BERHANU \\ $\mathrm{ESHO}^{* *}$
${ }^{*}$ School of Chemical and Bio-Engineering, Addis Ababa Institute of Technology, King George VI Street, P.O.Box 358 Addis Ababa, Ethiopia
${ }^{* *}$ College of Applied Science, Addis Ababa Science and Technology University, Addis Ababa, Ethiopia

\begin{abstract}
Ethiopia is known for its specialty Arabica coffees affected by mix-up. Physical and sensory properties of dry processed green coffee beans have been reported for the influence on the sensorial quality and coffee process optimization. The aim of this study was to investigate physical and sensory properties of sixteen varieties and to determine relationship of attributes. Physical properties of coffee beans were taken by measuring linear dimensions, densities and weight. Moreover, professional cuppers were analyzed sensory properties by using standard procedures. In this study, the longest $(10.40 \mathrm{~mm})$, the widest $(6.82 \mathrm{~mm})$ and the thickest $(4.48 \mathrm{~mm})$ varieties were Odicha, Feyate and Challa, respectively whereas the shortest $(8.28 \mathrm{~mm})$, narrowest $(5.59 \mathrm{~mm})$ and thinnest $(3.52 \mathrm{~mm})$ were 74110 , Mocha and Bultum, respectively. The shape \& make value of variety Bultum was "fair good" whereas variety Feyate was "very good". Furthermore, the results of "shape \& make" were significantly correlated with measured physical properties. The results indicate that most physical and sensory properties of coffee varieties have significant $(\mathrm{P} \leq 0.05$ differences. These properties were influenced by growing regions and variety difference. The outcome of this study can be used for coffee bean characterization and process optimization to improve beverage quality.
\end{abstract}

Keywords: Coffee Arabica, coffee variety, coffee dimensions, physical properties, sensory attributes

\section{INTRODUCTION}

Physical properties of coffee beans are important in designing of the transporting and processing equipment (Niveditha et al., 2013). Coffee quality depends on species choice, growing region and variety to the ultimate method of preparation for consumption (Scott, 2015). Processing of coffee from red cherry to brew is one of these factors that affects the quality of final product (Alves et al., 2017).

Ethiopia is one of the six top coffee Arabica growing country where about one fourth of its citizens directly or indirectly depends on coffee industry (ICO, 2018). Coffee in Ethiopia as a cash crop earns foreign currency is exported to different countries of the world for its unique attributes (Abdulmajid, 2014). According the studies of Tsegaye et al. (2014), there are improper preharvest and postharvest handlings in Ethiopian coffee

Received: 21.12.2020.

Accepted in revised form: 13.04.2020 industries that affect the uniqueness of each specialty coffee variety. Therefore, in order to address the requirements of consumers and keep the inherent properties of each variety; differentiating varieties has paramount importance in Ethiopian economy. One of the oldest and most commonly used method of coffee cherries processing into beans is natural or dry processing methods

On the other hand, some of the criteria that are used to evaluate the quality of coffee beans include bean size, color, shape, processing method and cup quality (Severa et al., 2013). Coffee quality associated to a set of factors that involves physicochemical and sensorial aspects depends on the postharvest handling and processing (Afonso et al., 2003 , Coradi et al., 2007, Lima et al., 2013). Moisture content, odor, shape, color, as well as size, and cross-section of the bean, have importance to coffee bean quality (Bicho et al., 2013). One of the common methods for the assessment of both the

\footnotetext{
${ }^{1}$ Corresponding author. E-Mail address: yishak.worku@aau.edu.et,yishak2001@gmail.com
} 
quality of green beans and coffee beverage is sensory analyses (Farah et al., 2006).

According to Chandrasekar and Viswanathan (1999) weight, size and volume of coffee green beans varied with growing regions for the Arabica coffee. Physical and sensory properties are important factors that influence acceptance and choices of coffee brew (Isleten and Karagul-Yuceer, 2006). In Ethiopian, to determine and develop database of physical properties of coffee beans, there is little information available that play an important role in designing and developing of specific processing and handling machines with their operations for the coffee varieties grown. Moreover, information on sensory quality along with the physical properties of specialty Ethiopian coffee varieties is limited. Therefore, the main objective of this study was to determine correlation of some physical properties with sensory quality for sixteen varieties of Ethiopia dry processed specialty green coffee beans selected from four agricultural research centers of the major coffee growing regions of the country.

\section{MATERIALS AND METHODS}

\section{Materials}

Sixteen Ethiopia specialty coffee varieties named Feyate, Odicha, Angefa, Qoti, Arusa, Bultum, Machara-1, Mocha, 744, 741, 7487, 74110, Menesibu, Haru-1, Challa and Sende.were obtained from four agricltural research centers. These coffees Arabica grow five major regions of the country as shown in the Figure 1. These agro-climate conditions includes Awada $\left[6^{\circ} 3^{\prime} \mathrm{N}\right.$ latitude, $38^{\circ} 3^{\prime} \mathrm{E}$ longitude, 1740 masl altitude, $11-28^{\circ} \mathrm{C}$ temperature and $1335 \mathrm{~mm}$ mean annual rainfall], Mechara [ $40^{\circ} 19.114 \mathrm{~N}$ latitude, $08^{\circ} 35.589 \mathrm{E}$ longitude, 1760 masl altitude, $16{ }^{\circ} \mathrm{C}$ and $963 \mathrm{~mm}$ annual average temperature rainfall respectively], Jimma $\left(7^{\circ} 40^{\prime} 9^{\prime \prime} \mathrm{N}\right.$ latitude, 36 $6^{\circ} 7^{\prime} 6 " \mathrm{E}$ longitude, 1753 masl altitude, 9$28^{\circ} \mathrm{C}$ temperature and $1561 \mathrm{~mm}$ annual rain fall) and Haru $\left(7^{\circ} 40^{\prime} 9^{\prime \prime} \mathrm{N}\right.$ latitude, $36^{\circ} 47^{\prime} 6^{\prime \prime} \mathrm{E}$ longitude, 1750 masl altitude, $18.9-26.8^{\circ} \mathrm{C}$ and $1561 \mathrm{~mm}$ annual rain fall).

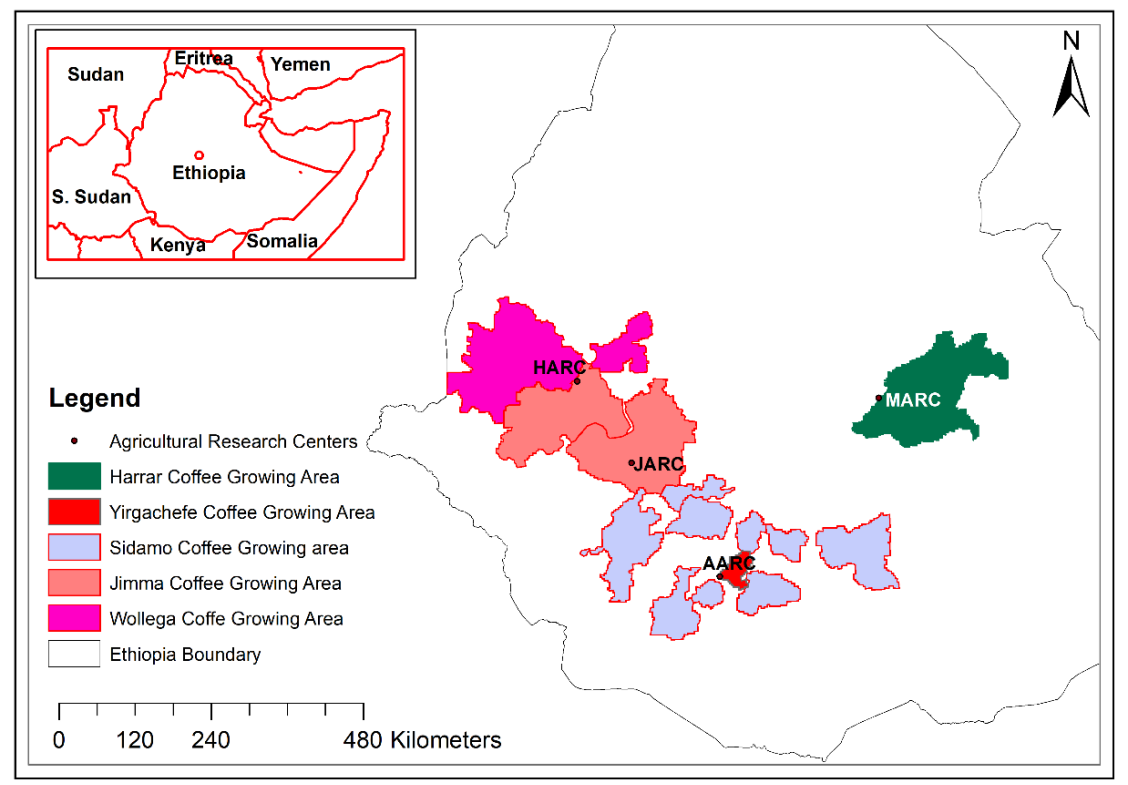

Figure 1. Location map of the sources (the four centers) for the sixteen varieties.

AARC: Awada Agricultural Research Center; JARC: Jimma Agricultural Research Center;

\section{Experimental setup and design}

In this study, the samples were given by different agricultural centers that are responsible for dissemination of these varieties to the respective growing regions of the country. Twelve kilograms of fully matured red cherry for each sixteen varieties were collected and their cherry removed to have green beans at the respective centers (i.e., AARC, MARC, JARC and HARC), which prepared based
MARC: Mechara Agricultural Research Center; HARC: Haru Agricultural Research Center; on dry processing method briefly explained by Coradi et al. (2007) and Taveria et al. (2015). The red cherries were collected at peak harvesting time in October to November, 2016. The green coffee beans were processed at each collecting center and transported to Addis Ababa institute of Technology (AAiT) in a continuous chilled container with icebox at $-4{ }^{\circ} \mathrm{C}$. The green coffee bean samples stored at $4{ }^{\circ} \mathrm{C}$ till analysis in AAiT School of 
Chemical \& Bioengineering. A randomized complete block design (RCBD) was used with three replications for both dimension and sensory analyses.

\section{Weight of dry processed green coffee beans}

The weights of individual beans were measured by digital balance (Accuracy 0.0001 g, ER-120A, Japan). Ten beans were selected at random from dry processed green coffee beans that are retained over screen 14 and weighed. The weighing was repeated three times and a single value was obtained by taking the average of the replicate (Pittia et al., 2007).

\section{Bulk and apparent densities}

The green coffee beans bulk density was measured using $500 \mathrm{~mL}$ measuring cylinder. The ratio between the weight and volume was used to evaluate the bulk density according to the method described by Pittia et al. (2007). The results of bulk density (equation 1) expressed as the mean value of three measurements.

Bulk Density $\left(\rho_{B}\right)=$

weight of washed green coffee beans

Bulk volume of washed green coffee beans

The green coffee beans apparent density (equation 2) was determined according to the method Olukunle and Akinnnuli (2012). The weight of ten beans was measured using a digital balance while taking the linear dimensions of each bean by a digital caliper. Triplicate measurements were taken to investigate the variance of the average values in the single coffee bean.

$$
\begin{aligned}
& \text { Apparent Density }\left(\rho_{A}\right)= \\
& \frac{\text { weight of washed green coffee bean }}{\text { Geometric volume of washed green coffee bean }}
\end{aligned}
$$

\section{Screen size and moisture content}

A round perforated screens were used to determine the green coffee beans size distributions. Screen holes are specified in 1/64-inch $(0.396 \mathrm{~mm})$. Green coffee beans retained above screen $14(5.544 \mathrm{~mm}$ diameter) were used to determine the percentage weights of each varieties. The screen size of coffee green beans was measured according to the method described by Oliveira et al. (2015). However, moisture content of green coffee beans was determined using standard method of AOAC 979.12 at $105^{\circ} \mathrm{C}$ for $16 \mathrm{~h}$ (AOAC, 2007).

\section{Dimensions of dry processed coffee beans}

Linear dimensions

A digital caliper (Vernier Caliper, $150 \mathrm{~mm} / 6$ inch, China) was used to measure the three linear dimensions; length (major), width (intermediate), and thickness (minor) of 30 green coffee beans from each variety (Mohsenin (1986), Coradi et al. (2007), Olukunle and Akinnnuli (2012)).

\section{Calculated dimensions}

The volume, cross-sectional, cross-sectional area, sphericity, shape index and coefficient of contact surface of dry processed green coffee beans were calculated using the relationships given by the method described by Mohsenin (1986), as:

Volume $(\mathrm{V})$ :

$$
V=\frac{\pi}{6} L W T, \mathrm{~mm}^{3}
$$

Cross - sectional area (CSA):

$$
C S A=\frac{\pi}{4} \frac{(L+W+T)^{2}}{3}, \mathrm{~mm}^{2}
$$

Sphericity (S):

$$
S=100 \frac{(L W T)^{0.333}}{L}, \%
$$

Shape Index (SI):

$$
S I=\frac{L}{\sqrt{(W * T)}}
$$

Coefficient of contact surface (CCS):

$$
C C S=\frac{F S A-T S A}{F S A} * 100
$$

Where: FSA (frontal surface area):

$$
\begin{gathered}
F S A=\frac{\pi}{4} * L * W, \mathrm{~mm}^{2} \\
\text { TSA (transverse surface area): } \\
T S A=\frac{\pi}{4} * T * W, \mathrm{~mm}^{2}
\end{gathered}
$$

where, $\mathrm{L}, \mathrm{W}$, and $\mathrm{T}$ are representing the linear dimensions length, width and thickness, respectively.

\section{Sensory quality of dry processed green coffee beans}

Sensory analysis was carried out at Jimma Agricultural Centre Laboratory, Jimma, Ethiopia. Three professional taste panels were involved in determining sensory of dry processed coffee green beans according to the methods of Sualeh and Mekonnen (2015). Scores of the shape \& make, color and odor for the sixteen varieties of dry processed green coffee beans were given according to Table 1.

\section{Experimental design and statistical analysis}

JMP Pro 13 (version 13.0.0, 2016, SAS Institute Inc., USA,) statistical software used for the analysis of variance (ANOVA) on each of the sixteen green coffee beans data. The results of physical and sensory properties for each variety were expressed as mean $\pm \mathrm{SD}$. In addition, the means separation was performed by Tukey's test at $\mathrm{P} \leq 0.05$ differences. 
Table 1 . The scale of dry processed green coffee beans used by sensory panel ( Sualeh and Mekonnen, 2015)

\begin{tabular}{cccccc}
\hline SM & \multicolumn{3}{c}{ Color } & \multicolumn{3}{c}{ Odor } \\
\hline Quality & Pts & Quality & Pts & Quality & Pts \\
\hline Very Good & 15 & Bluish & 15 & Clean & 10 \\
Good & 12 & Grayish & 12 & Fair Clean & 8 \\
Fair Good & 10 & Greenish & 10 & Trace & 6 \\
Average & 8 & Coated & 8 & Light & 4 \\
Mixed & 6 & Faded & 6 & Moderate & 2 \\
Small & 4 & White & 4 & Strong & 0 \\
\hline
\end{tabular}

$\mathrm{SM}=$ shape and make

\section{RESULTS AND DISCUSSIONS}

\section{Physical parameters of dry processed green coffee beans}

The physical properties can be used to determine the quality attribute of the coffee in order to use machinery design, storage and handling (Ismail et al., 2014). Coefficient of variation (CV) can be used to differentiate the measured parameters about their means when the shape and sizes of green coffee beans are irregular nature (Eke et al., 2007). The physical parameters (weight of bean, bulk density, apparent density, weight over screen 14 and moisture content) of the dry processed green beans were investigated and ranged from 0.11 to $0.19 \mathrm{~g}$, 0.66 to $0.73 \mathrm{~g} / \mathrm{mL}, 0.98$ to $1.68 \mathrm{~g} / \mathrm{mL}, 71.94$ to 99.09 $\%$ and 9.77 to $13.10 \%$ with average values of 0.15 g, $0.68 \mathrm{~g} / \mathrm{mL}, 1.35 \mathrm{~g} / \mathrm{mL}, 92.82 \%$ and $11.17 \%$ respectively (Table 2). The other physical parameters (linear and calculated dimensions) were showed in Figure 2 and Table 3.

\section{Weight}

The minimum, maximum and mean values of weight of dry processed green coffee bean were $0.11,0.18$ and $0.15 \mathrm{~g}$, respectively. The minimum weight $(0.11 \mathrm{~g})$ was for all Mechara varieties whereas the maximum $(0.18 \mathrm{~g})$ for Sende variety from Haru. The mean weight of green bean of the different varieties was $0.15 \mathrm{~g}$ which is lower than $0.19 \mathrm{~g}$ of the previous study by Chandrasekar and Viswanathan (1999). These may be due to the agroecological and varietal differences. Coffee varieties grown at Mechara were lighter $(0.11 \mathrm{~g}$ average weight) than coffee grown in the other centers (Table 2). Mean comparison showed significant differences $(\mathrm{P} \leq 0.05)$ among coffee varieties in their weight. This may be due to the growing season as well as agro-ecological and varietal differences.

\section{Bulk and apparent densities}

Botanic, horticultural, processing, storage and handling factors significantly influence the bulk density of green coffee beans, whilst their roasting behavior and conditions (ISO, 1995). For choosing

a proper roast profile, knowing density is one of the most basic information a roaster needs (Wilson, 2018). The bulk density is considered for determination of contacting capacity, designing hopper dimensions in cleaning and grading equipment (El Fawal et al., 2009). According to Table 2, the bulk density of dry processed green coffee beans $(0.61-0.68 \mathrm{~g} / \mathrm{mL})$ is lower than 0.84 $\mathrm{g} / \mathrm{mL}$ of soya bean by Mohsenin (1986), $0.78 \mathrm{~g} / \mathrm{mL}$ of Canavalia ensiformis by Eke et al. (2007) and $(0.74-0.76 \mathrm{~g} / \mathrm{mL})$ of African yam bean by Taser et al. (2005). The apparent density $<1 \mathrm{~g} / \mathrm{mL}$ indicates that the Canavalia seeds are lighter than water as per the result of Niveditha et al. (2013). Whereas, the dry processed green coffee beans apparent densities were $>1 \mathrm{~g} / \mathrm{mL}$ (Table 2) that is greater than water density. Therefore, the data will be useful for optimum usage of cleaning of coffee. The results of bulk density for most varieties were significantly different at $\mathrm{P} \leq 0.05$ whereas the apparent densities were not for most varieties (Table 2).

\section{Weight of Beans Retained on screen 14}

Sualeh and Mekonnen (2015) presented in their manual that pre- and post-harvest processing techniques, grading, packing and transporting are factors that determine coffee quality. According to Table 2, the average weight percent over 14 - inch screen was lower $(75.75 \%)$ for Mechara varieties and higher $(96.60 \%)$ for Awada's. The minimum, maximum, and mean percent weights over 14 -inch screen size were 63.94, 98.73 and $90.74 \%$, respectively. The lowest value of weight percent over 14 - inch screen (63.94 \%) was for variety Bultum from Mechara and the highest (98.73\%) for 7487 from Awada. The results of weight percent over 14 - inch screen for most varieties were significantly different at $\mathrm{P} \leq 0.05$ (Table 2). This may be due to varietal and growing region variations. 


\section{Moisture content}

Moisture content is an important factor for preservation of coffee quality when it is more than $12 \%$ favor the growth of molds and cause off flavors that affect the quality of coffee (Koskei et al., 2015). According to Table 2, the average results of moisture content were lower (10.90 \%) for Jimma varieties and higher (13.26 \%) for Awada's. The minimum, maximum, and mean results of moisture content were $10.17,14.30$ and $12.13 \%$, respectively. The lowest moisture content $(10.17 \%)$ was for variety 7487 from Jimma and the highest $(14.35 \%)$ for Qoti from Awada.

Table 2. Weight of bean, bulk and apparent densities, weight over screen 14 and moisture content.

\begin{tabular}{llrrrrr}
\hline Center & Variety & WB $[\mathrm{g}]$ & $\mathrm{BD}[\mathrm{g} / \mathrm{mL}]$ & $\mathrm{AD}[\mathrm{g} / \mathrm{mL}]$ & WBR [\%] & $\% \mathrm{MC}\left[^{1} \mathrm{db}\right]$ \\
\hline Awada & Feyate & $0.17^{\mathrm{ab}}$ & $0.61^{\mathrm{g}}$ & $1.17^{\mathrm{abc}}$ & $97.99^{\mathrm{b}}$ & $11.83^{\mathrm{cde}}$ \\
& Odicha & $0.17^{\mathrm{ab}}$ & $0.62^{\mathrm{efg}}$ & $1.23^{\mathrm{abc}}$ & $97.20^{\mathrm{d}}$ & $12.88^{\mathrm{bc}}$ \\
& Angefa & $0.17^{\mathrm{ab}}$ & $0.63^{\mathrm{efg}}$ & $1.27^{\mathrm{abc}}$ & $95.70^{\mathrm{f}}$ & $13.98^{\mathrm{ab}}$ \\
& Qoti & $0.15^{\mathrm{c}}$ & $0.62^{\mathrm{fg}}$ & $1.09^{\mathrm{abc}}$ & $95.51^{\mathrm{h}}$ & $14.35^{\mathrm{a}}$ \\
\hline Mechara & Arusa & $0.11^{\mathrm{d}}$ & $0.67^{\mathrm{a}}$ & $1.13^{\mathrm{abc}}$ & $84.36^{1}$ & $12.27^{\mathrm{cd}}$ \\
& Bultum & $0.11^{\mathrm{d}}$ & $0.67^{\mathrm{a}}$ & $1.04^{\mathrm{bc}}$ & $63.94^{\mathrm{n}}$ & $11.97^{\mathrm{cd}}$ \\
& Mechara-1 & $0.11^{\mathrm{d}}$ & $0.68^{\mathrm{a}}$ & $1.02^{\mathrm{c}}$ & $84.33^{1}$ & $11.83^{\mathrm{cde}}$ \\
& Mocha & $0.11^{\mathrm{d}}$ & $0.66^{\mathrm{ab}}$ & $1.12^{\mathrm{abc}}$ & $70.37^{\mathrm{m}}$ & $11.83^{\mathrm{cde}}$ \\
\hline Jimma & 744 & $0.15^{\mathrm{c}}$ & $0.65^{\mathrm{bc}}$ & $1.48^{\mathrm{a}}$ & $96.71^{\mathrm{e}}$ & $11.87^{\mathrm{cd}}$ \\
& 741 & $0.15^{\mathrm{c}}$ & $0.67^{\mathrm{a}}$ & $1.32^{\mathrm{abc}}$ & $90.54^{\mathrm{k}}$ & $10.43^{\mathrm{ef}}$ \\
& 7487 & $0.15^{\mathrm{c}}$ & $0.67^{\mathrm{a}}$ & $1.39^{\mathrm{abc}}$ & $98.73^{\mathrm{a}}$ & $10.17^{\mathrm{f}}$ \\
& 74110 & $0.15^{\mathrm{c}}$ & $0.68^{\mathrm{a}}$ & $1.36^{\mathrm{abc}}$ & $95.55^{\mathrm{g}}$ & $11.13^{\mathrm{def}}$ \\
\hline Haru & Menesibu & $0.15^{\mathrm{c}}$ & $0.63^{\mathrm{de}}$ & $1.32^{\mathrm{abc}}$ & $93.56^{\mathrm{j}}$ & $11.23^{\mathrm{def}}$ \\
& Haru-1 & $0.16^{\mathrm{bc}}$ & $0.62^{\mathrm{efg}}$ & $1.44^{\mathrm{ab}}$ & $94.26^{\mathrm{i}}$ & $12.43^{\mathrm{cd}}$ \\
& Challa & $0.16^{\mathrm{bc}}$ & $0.63^{\mathrm{def}}$ & $1.31^{\mathrm{abc}}$ & $95.73^{\mathrm{f}}$ & $12.93^{\mathrm{abc}}$ \\
& Sende & $0.18^{\mathrm{a}}$ & $0.64^{\mathrm{cd}}$ & $1.22^{\mathrm{abc}}$ & $97.42^{\mathrm{c}}$ & $12.90^{\mathrm{bc}}$ \\
\hline & SE & 0.003 & 0.003 & 0.08 & 0.01 & 0.27 \\
\hline
\end{tabular}

Values are least square means and those with different superscript letters are significantly different $(\mathrm{P} \leq 0.05)$;

$\mathrm{WB}=$ weight of bean, $\mathrm{BD}=$ bulk density; $\mathrm{AP}=$ apparent density; $\mathrm{WBR}=$ weight of beans retained over screen $14 ; \mathrm{MC}$ $=$ moisture content; ${ }^{1} \mathrm{db}=\mathrm{dry}$ base; $\mathrm{SE}=$ standard error [of means]

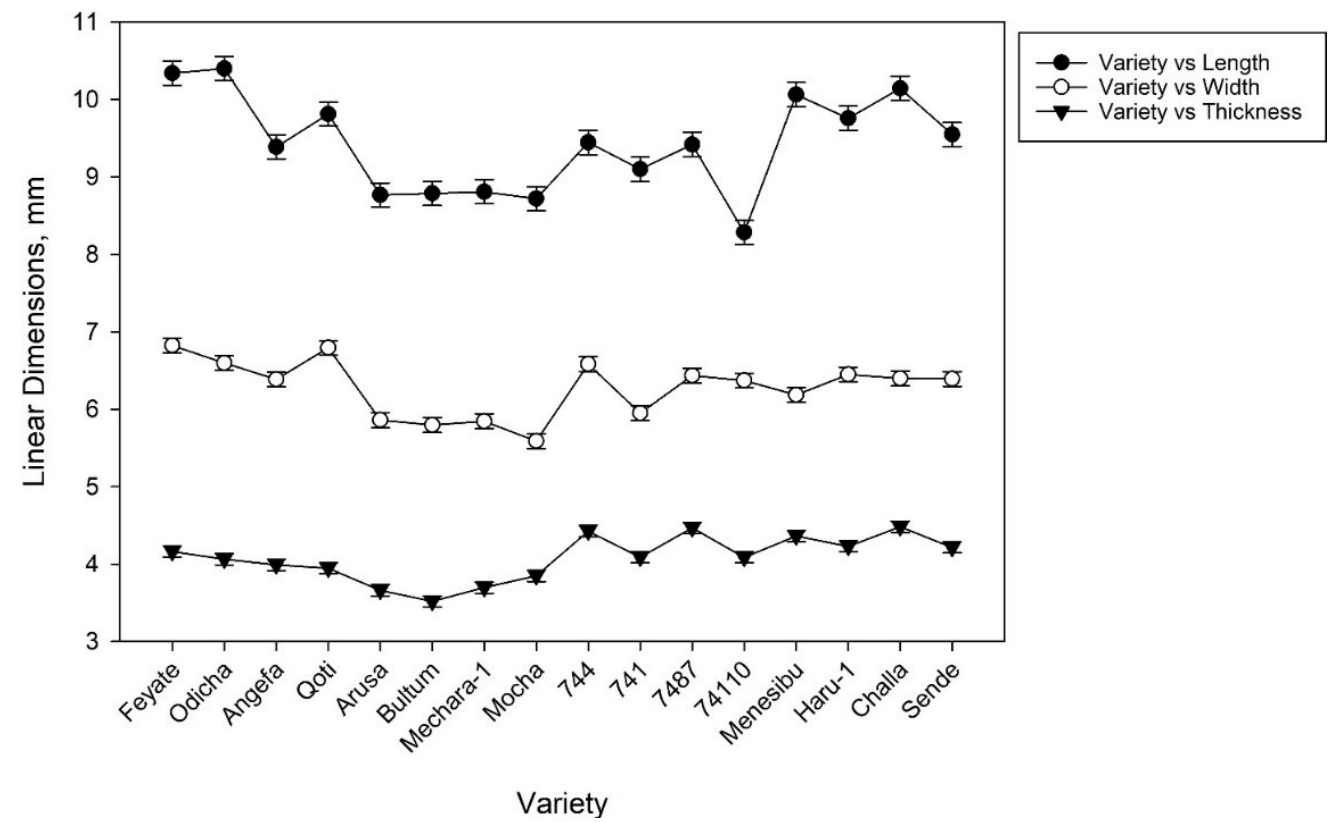

Figure 2. Frequency distributions of linear dimensions dry processed coffee beans varieties 


\section{Linear dimensions}

Size is one of the important properties for design of handling, processing, and preparation of green coffee beans (Chandrasekar and Viswanathan, 1999). Main dimensions of green coffee beans are also used for selecting, designing suitable size of screen meshes and determining proper method of separation (El Fawal et al., 2009).

In this study, the longest $(10.40 \mathrm{~mm})$, the widest $(6.82 \mathrm{~mm})$ and the thickest $(4.48 \mathrm{~mm})$ varieties were Odicha, Feyate and Challa, respectively whereas the shortest $(8.28 \mathrm{~mm})$, narrowest $(5.59$ $\mathrm{mm})$ and thinnest $(3.52 \mathrm{~mm})$ were 74110 , Mocha and Bultum, respectively. The average linear dimensions (length, width and thickness) of coffee varieties of dry processed green coffee beans from Mechara have the smallest values and the length and width sizes of Awada varieties have the highest values whereas the average thickness size of Haru varieties was the largest.

The obtained results of dimensions were smaller than the results stated by Chandrasekar and Viswanathan (1999) of Indian \& by Ismail et al. (2014) of Yemenian coffee beans and higher than observed by Olukunle and Akinnnuli (2012) of Nigerian Arabica coffee beans. This difference may be due to agro-ecological and varietal differences. According to the mean comparison, there were significance differences $(\mathrm{P} \leq 0.05)$ among the dry processed coffee green beans in terms of varieties length, width and thickness.

\section{Calculated dimensions}

Volume, cross-sectional area (CSA), and sphericity (S)

According to Niveditha et al. (2013) size, surface area and volume of green coffee beans have importance in bulk handling as well as heat and mass transport phenomena. Green coffee beans are graded based on size that has correlation with quality. If all other factors are equal, however, a larger coffee bean will generally produce a higher quality brew than a smaller one (Scott, 2015). The study of Chandrasekar and Viswanathan (1999) on mass, size and volume Kenyan Arabica coffee beans showed variation with the growing regions. Results of volume, CSA, and S of dry processed coffee beans are depicted in Table 3 . The values of geometric dimensions (volume, cross-sectional area, and sphericity) ranged from 97.17 to 158.30 $\mathrm{mm}^{3}, 85.55$ to $122.12 \mathrm{~mm}^{2}$, and 63.11 to $72.10 \%$ with average values of $128.8 \mathrm{~mm}^{3}, 103.71 \mathrm{~mm}^{2}$ and $66.45 \%$, respectively for all varieties of dry processed coffee beans (Table 3).Volume

The volume of green coffee bean has important role during roasting to expand the bean (Ismail et al.,
2014). Obtained green coffee bean volume in the range of minimum mean and maximum are 94.89 , 127.95 and $153.85 \mathrm{~mm}^{3}$ respectively (Table 1 ). The smallest volume $\left(94.89 \mathrm{~mm}^{3}\right)$ obtained for Bultum variety from Mechara and the highest (153.85 $\mathrm{mm}^{3}$ ) for Feyate from Awada. The Mechara varieties taken for this study have smaller size in volume than from the overall mean volume (126.70 $\mathrm{mm}^{3}$ ) whereas the Haru varieties have larger values. This variation may be due to varietal and growing region difference. The mean comparison showed significant differences $(\mathrm{P} \leq 0.05)$ among volumes for most coffee varieties studied.

\section{Cross-sectional area}

Surface area of irregular shaped seeds have critical use in designing cleaners, separators and conveyors (Vishwakarma et al., 2012). Minimum, mean and maximum values of cross-sectional area of the green coffee bean are 86.71, 103.01 and 119.15 $\mathrm{mm}^{2}$ respectively. The average cross-section areas of Awada $\left(112.22 \mathrm{~mm}^{2}\right)$ varieties was the highest whereas Mechara $\left(87.27 \mathrm{~mm}^{2}\right)$ was the lowest. The smallest cross-section area $\left(86.21 \mathrm{~mm}^{2}\right)$ obtained for variety Bultum from Mechara and the highest $\left(119.15 \mathrm{~mm}^{2}\right)$ for variety Feyate from Awada. The mean values of cross-sectional area were significantly different at $(\mathrm{P} \leq 0.05)$.

\section{Sphericity}

When sphericity of green coffee bean is closer to $100 \%$ it will tend to roll either to the major, intermediate or minor axis (Niveditha et al., 2013). The average sphericity value of green bean Awada's varieties $(64.68 \%)$ is the lowest while Jimma's varieties $(69.05 \%)$ is the highest. Out of the experimented varieties, the minimum percentage value of sphericity is $62.82 \%$ for Awada's variety (Odicha) whereas the maximum sphericity value is $69.05 \%$ for Jimma's variety (74110). As per the previous study by Ismail et al. (2014), the spericity value (0.63) of Liberica coffee of Malaysia is smaller than the mean value of sphericity (0.66) for all varieties of the current study for the Arabica coffee of Ethiopia. This may be due to agro-ecological and varietal differences. The mean comparison was showed significant differences $(\mathrm{P} \leq 0.05)$ among the cross-sectional areas for most coffee varieties under study.

\section{Shape-index (SI)}

According to the study of Abdel El-Elah (2008) on engineering properties of Yemeni Coffee, the SI is used to evaluate whether the shape is oval $(\mathrm{SI}>1.5)$ or spherical $(\mathrm{SI} \leq 1.5)$. The obtained results of $\mathrm{SI}$ of dry processed green coffee beans of each varieties 
are shown in Table 3. The maximum, minimum and average shape index of coffee varieties were $2.01,1.63$ and 1.87, respectively. According to definition by Abdel El-Elah (2008) the shape of all the coffee varieties were found to have an oval shape. The lowest shape-index (1.63) was found for variety 74110 from Jimma whereas the highest (2.01) for Odicha from Awada. The mean comparison had significant differences $(\mathrm{P} \leq 0.05)$ among shape indices for most studied varieties.

\section{Coefficient of contact surface (CCS)}

CCS is an important parameter to evaluate contact surface between the bean and surfaces such as cleaning, roasting and milling machines (Abdel ElElah, 2008). The obtained results of coefficient of contact surface of dry processed green coffee beans of each varieties are shown in Table 3. The maximum, minimum and average CCS of coffee varieties were $60.78,50.49$ and $56.38 \mathrm{~mm}^{2}$, respectively (Table 3 ). The results of coefficient of contact surface are significantly different from the results of Yemeni Arabica coffee by Abdel El-Elah (2008). This is due to the varietal and agro-ecological differences.

The mean values of geometric dimensions were significantly different at $(\mathrm{P} \leq 0.05)$.

\section{Sensory quality of dry processed green coffee beans}

Shape \& make indicates the bean boldness and uniformity in coffee. It also has an important physical characteristic that affects the roasting process and subsequently reduces cup quality. The shape \& make evaluated as very good, good, fairly good, mixed, and small and weighted, moreover, both color and odor of green beans are another physical properties of coffee quality (Sualeh and Mekonnen, 2015). Having uniform shape \& make is good green bean character if not it affects the roasting process by having non-uniform roasted beans that subsequently reduces cup quality. According to Table 4, the sensory quality (shape \& make, color and odor) of dry processed green coffee beans range from 10.67 to $14.00,11.67$ to 14.00 and 9.33 to 10.00 with average values of 12.54 , 12.85 and 9.88 , respectively. The average shape \& make value of Mechara's varieties was in between "fair good" and "good" whereas the rest showed between "good" and "very good". The shape \& make value of variety W3382 from Mechara was near to "fair good" whereas variety WAWV-A from Awada near to "very good". Mean comparison was showed significant differences ( $\mathrm{P}$ $\leq 0.05$ ) among coffee varieties in their shape $\&$ make. This may be due to varietal and growing region differences. Mean comparison also showed no significant differences $(\mathrm{P} \leq 0.05)$ among coffee varieties color and odor. This may be due to the harvested red cherries were fully ripped, matured and well-processed into green beans using the dry processed process.

Table 3. Calculated dimensions of dry processed green coffee beans

\begin{tabular}{clrrrrr}
\hline Center & Variety & Volume $\left[\mathrm{mm}^{3}\right]$ & CSA $\left[\mathrm{mm}^{2}\right]$ & Sphericity $[\%]$ & \multicolumn{1}{c}{ SI } & CCS $\left[\mathrm{mm}^{2}\right]$ \\
\hline Awada & Feyate & $153.85^{\mathrm{a}}$ & $119.15^{\mathrm{a}}$ & $64.21^{\mathrm{de}}$ & $1.95^{\mathrm{ab}}$ & $59.68^{\mathrm{ab}}$ \\
& Odicha & $145.96^{\mathrm{ab}}$ & $116.21^{\mathrm{ab}}$ & $62.82^{\mathrm{e}}$ & $2.01^{\mathrm{a}}$ & $60.78^{\mathrm{a}}$ \\
& Angefa & $126.30^{\mathrm{bcd}}$ & $102.73^{\mathrm{cde}}$ & $66.25^{\mathrm{b}-\mathrm{e}}$ & $1.87^{\mathrm{abc}}$ & $57.05^{\mathrm{a}-\mathrm{e}}$ \\
& Qoti & $137.91^{\mathrm{ab}}$ & $110.81^{\mathrm{abc}}$ & $65.43^{\mathrm{b}-\mathrm{e}}$ & $1.90^{\mathrm{abc}}$ & $59.47^{\mathrm{ab}}$ \\
\hline Mechara & Arusa & $98.40^{\mathrm{ef}}$ & $87.91^{\mathrm{f}}$ & $65.45^{\mathrm{b}-\mathrm{e}}$ & $1.90^{\mathrm{abc}}$ & $57.63^{\mathrm{a}-\mathrm{d}}$ \\
& Bultum & $94.89^{\mathrm{f}}$ & $86.21^{\mathrm{f}}$ & $64.15^{\mathrm{de}}$ & $1.95^{\mathrm{ab}}$ & $59.84^{\mathrm{ab}}$ \\
& Mechara-1 & $100.26^{\mathrm{ef}}$ & $88.50^{\mathrm{f}}$ & $65.19^{\mathrm{cde}}$ & $1.91^{\mathrm{abc}}$ & $57.90^{\mathrm{abc}}$ \\
& Mocha & $97.84^{\mathrm{ef}}$ & $86.48^{\mathrm{f}}$ & $65.57^{\mathrm{b}-\mathrm{e}}$ & $1.89^{\mathrm{abc}}$ & $55.52^{\mathrm{b}-\mathrm{e}}$ \\
\hline \multirow{2}{*}{ Jimma } & 744 & $143.66^{\mathrm{ab}}$ & $109.73^{\mathrm{abc}}$ & $68.87^{\mathrm{ab}}$ & $1.76^{\mathrm{cd}}$ & $52.89^{\mathrm{def}}$ \\
& 741 & $115.40^{\mathrm{cde}}$ & $96.04^{\mathrm{def}}$ & $66.44^{\mathrm{bcd}}$ & $1.85^{\mathrm{bc}}$ & $54.67^{\mathrm{c}-\mathrm{f}}$ \\
& 7487 & $141.46^{\mathrm{ab}}$ & $108.40^{\mathrm{abc}}$ & $68.51^{\mathrm{bc}}$ & $1.77^{\mathrm{cd}}$ & $52.28^{\mathrm{ef}}$ \\
& 74110 & $113.90^{\mathrm{def}}$ & $92.25^{\mathrm{ef}}$ & $72.38^{\mathrm{a}}$ & $1.63^{\mathrm{d}}$ & $50.49^{\mathrm{f}}$ \\
\hline \multirow{2}{*}{ Haru } & Menesibu & $143.22^{\mathrm{ab}}$ & $111.75^{\mathrm{abc}}$ & $64.37^{\mathrm{de}}$ & $1.95^{\mathrm{ab}}$ & $56.34^{\mathrm{a}-\mathrm{e}}$ \\
& Haru-1 & $139.23^{\mathrm{ab}}$ & $109.60^{\mathrm{abc}}$ & $65.88^{\mathrm{b}-\mathrm{e}}$ & $1.88^{\mathrm{abc}}$ & $56.41^{\mathrm{a}-\mathrm{e}}$ \\
& Challa & $152.18^{\mathrm{a}}$ & $115.92^{\mathrm{ab}}$ & $65.32^{\mathrm{b}-\mathrm{e}}$ & $1.90^{\mathrm{abc}}$ & $55.60^{\mathrm{b}-\mathrm{e}}$ \\
& Sende & $134.77^{\mathrm{abc}}$ & $106.55^{\mathrm{bcd}}$ & $66.61^{\mathrm{bcd}}$ & $1.85^{\mathrm{bc}}$ & $55.59^{\mathrm{b}-\mathrm{e}}$ \\
\hline & SE & 4.10 & 2.29 & 0.74 & 0.03 & 0.99 \\
\hline
\end{tabular}

Values are least square means and those with different superscript letters are significantly different $(\mathrm{P} \leq 0.05)$; CSA $=$ contact surface area; $\mathrm{SI}=$ shape index; $\mathrm{CSS}=$ coefficient contact surface area; $\mathrm{SE}=$ standard error [of means]; 


\section{Multivariate Analysis}

Pearson correlations between each pair of variables are shown in Table 5. The range of correlation coefficients $(-1$ to +1$)$ measure the strength of the linear relationship between the variables. All values with superscripts ** $(\mathrm{P}<$ $0.001)$ and $*(0.01<\mathrm{P}<0.05)$ indicated statistically highly significant and significant, respectively. The following pairs of variables (sphericity vs CCS; sphericity vs shape index; sphericity vs bulk density; and CCS vs bulk density) were negatively correlated. The possible reason for negatively correlation of sphericity may be due to the result of this study showed the green coffee beans shape are oval. Whereas, weight of bean vs weight over screen 14 inch; weight of bean vs apparent density; weight of bean vs shape \& make; and shape index vs CCS were positively correlated.

Table 4. Sensory qualities of dry processed green coffee beans

\begin{tabular}{ccccc}
\hline Center & Variety & Shape \& Make & Color & Odor \\
\hline Awada & Feyate & $14.00^{\mathrm{a}}$ & $12.67^{\mathrm{a}}$ & $9.33^{\mathrm{a}}$ \\
& Odicha & $13.67^{\mathrm{a}}$ & $12.67^{\mathrm{a}}$ & $9.67^{\mathrm{a}}$ \\
& Angefa & $13.00^{\mathrm{a}}$ & $12.67^{\mathrm{a}}$ & $9.17^{\mathrm{a}}$ \\
& Qoti & $12.83^{\mathrm{a}}$ & $12.67^{\mathrm{a}}$ & $9.83^{\mathrm{a}}$ \\
\hline Mechara & Arusa & $12.33^{\mathrm{a}}$ & $12.33^{\mathrm{a}}$ & $10.00^{\mathrm{a}}$ \\
& Bultum & $12.83^{\mathrm{a}}$ & $12.67^{\mathrm{a}}$ & $9.83^{\mathrm{a}}$ \\
& Mechara-1 & $13.33^{\mathrm{a}}$ & $13.67^{\mathrm{a}}$ & $10.00^{\mathrm{a}}$ \\
& Mocha & $11.83^{\mathrm{a}}$ & $12.67^{\mathrm{a}}$ & $10.00^{\mathrm{a}}$ \\
\hline Jimma & 744 & $11.33^{\mathrm{a}}$ & $11.67^{\mathrm{a}}$ & $9.17^{\mathrm{a}}$ \\
& 741 & $11.33^{\mathrm{a}}$ & $11.67^{\mathrm{a}}$ & $9.00^{\mathrm{a}}$ \\
& 7487 & $12.00^{\mathrm{a}}$ & $12.33^{\mathrm{a}}$ & $9.33^{\mathrm{a}}$ \\
& 74110 & $12.00^{\mathrm{a}}$ & $12.00^{\mathrm{a}}$ & $9.33^{\mathrm{a}}$ \\
\hline Haru & Menesibu & $13.00^{\mathrm{a}}$ & $12.67^{\mathrm{a}}$ & $9.67^{\mathrm{a}}$ \\
& Haru-1 & $13.33^{\mathrm{a}}$ & $13.33^{\mathrm{a}}$ & $9.50^{\mathrm{a}}$ \\
& Challa & $13.00^{\mathrm{a}}$ & $13.00^{\mathrm{a}}$ & $9.17^{\mathrm{a}}$ \\
& Sende & $13.17^{\mathrm{a}}$ & $12.67^{\mathrm{a}}$ & $9.83^{\mathrm{a}}$ \\
\hline & & 0.61 & $0.42^{\mathrm{a}}$ & $0.25^{\mathrm{a}}$
\end{tabular}

Values are least square means and those with different superscript letters are significantly different $(\mathrm{P} \leq 0.05) ; \mathrm{SE}=$ standard error [of means]

Table 5. Partial correlation coefficients between each pair of variables for dry processed green coffee beans

\begin{tabular}{|c|c|c|c|c|c|c|c|c|c|c|c|c|}
\hline & $\begin{array}{c}\text { Volume } \\
{\left[\mathrm{mm}^{3}\right]}\end{array}$ & $\begin{array}{c}\mathrm{CSA} \\
{\left[\mathrm{mm}^{2}\right]}\end{array}$ & $\mathrm{S}[\%]$ & SI & $\begin{array}{c}\mathrm{CCS} \\
{\left[\mathrm{mm}^{2}\right]}\end{array}$ & SM & Color & Odor & WB [g] & $\begin{array}{c}\mathrm{BD} \\
{[\mathrm{g} / \mathrm{mL}]}\end{array}$ & $\begin{array}{c}\mathrm{AD} \\
{[\mathrm{g} / \mathrm{mL}]}\end{array}$ & $\begin{array}{cc}\text { WBR } & \% \mathrm{MC} \\
{[\%]} & {\left[{ }^{1} \mathrm{db}\right]}\end{array}$ \\
\hline \multicolumn{13}{|l|}{ Volume } \\
\hline CSA & $0.99 * *$ & & & & & & & & & & & \\
\hline $\mathrm{S}$ & $0.84 * *$ & $0.83 * *$ & & & & & & & & & & \\
\hline SI & $0.72 * *$ & $0.77 * *$ & 0.7109 & & & & & & & & & \\
\hline CCS & $0.72 * *$ & $0.79 * *$ & $0.69 * *$ & $0.93 * *$ & & & & & & & & \\
\hline SM & -0.05 & 0.001 & -0.25 & 0.02 & 0.08 & & & & & & & \\
\hline Color & -0.19 & -0.17 & $-0.35^{*}$ & -0.08 & -0.02 & $0.61 * *$ & & & & & & \\
\hline Odor & -0.12 & -0.11 & -0.14 & 0.13 & 0.15 & 0.10 & $0.36^{*}$ & & & & & \\
\hline WB & $0.39 *$ & $0.38^{*}$ & 0.09 & -0.09 & -0.001 & 0.19 & -0.11 & $-0.38 * *$ & & & & \\
\hline $\mathrm{BD}$ & $-0.35^{*}$ & $-0.38 *$ & 0.05 & -0.07 & -0.15 & $-0.41^{*}$ & -0.16 & 0.13 & $-0.68 * *$ & & & \\
\hline $\mathrm{AD}$ & 0.25 & 0.20 & 0.16 & -0.17 & -0.18 & -0.19 & -0.27 & $-0.46 * *$ & $0.40 *$ & -0.15 & & \\
\hline WBR & $0.35^{*}$ & $0.36^{*}$ & 0.15 & -0.13 & -0.07 & 0.11 & -0.10 & $-0.38 *$ & $0.82 * *$ & $-0.51 * *$ & $0.48 * *$ & \\
\hline$\% \mathrm{M}$ & $0.09 *$ & 0.13 & $-0.07 *$ & 0.05 & 0.13 & $0.32 *$ & $0.35^{*}$ & 0.15 & 0.26 & $-0.59 * *$ & -0.18 & 0.11 \\
\hline
\end{tabular}

** Highly significant $(\mathrm{P}<0.001)$ and $*$ Significant $(0.01<\mathrm{P}<0.05) . \mathrm{CSA}=$ contact surface area; $\mathrm{S}=$ sphericity; $\mathrm{SI}=$ shape index; $\mathrm{CSS}=$ coefficient contact surface area; $\mathrm{SM}=$ shape $\&$ make; $\mathrm{WB}=$ weight of bean; $\mathrm{BD}=$ bulk density; $\mathrm{AP}$ $=$ apparent density; $\mathrm{WBR}=$ weight of beans retained on screen $14 ; \mathrm{MC}=$ moisture content; ${ }^{1} \mathrm{db}=\mathrm{dry}$ base

\section{CONCLUSIONS}

From this study, the physical and sensory quality of dry processed green coffee beans were influenced by varietal difference. Moreover, the physical parameters of green coffee beans (weight, bulk \& apparent densities, weight over 14 " screen and moisture content); linear dimensions (length, width 
and thickness); geometric dimensions (volume, CSA, sphericity, SI and CCS) and sensory (shape \& make, color, and odor) showed statistically significant correlation. For the sixteen Ethiopian specialty coffee varieties this study revealed that the physical and sensory quality indicators were statistically significant. These findings have importance for selecting sorting, separating and cleaning equipment. And also, they are used in designing suitable size of these equipment as well as quality differentiation of Ethiopian coffee varieties.

\section{ACKNOWLEDGEMENTS}

Authors acknowledge Agricultural Research Centers (Awada, Mechara, Jimma and Haru) for providing red coffee cherries as well as processing them into green coffee beans by dry processing method in their facilities. Moreover, we acknowledge Jimma Agricultural Research Center for conducting sensory analysis of green coffee beans by its professional cuppers.

\section{CONFLICT OF INTEREST}

In this manuscript we declare that there is no any form of conflict of interest.

\section{REFERENCE}

1. abdel El-Elah, O. S. 2008. Determination of Engineering and Chemical Properties of some Yemeni Coffee Varieties. The 15th. Annual Conference of the Misr Society of Ag. Eng. Yemen.

2. Abdulmajid, A. M. 2014. Sensory Evaluation of beverage characteristics and biochemical components of Coffee Genotypes Advances in Food Science and Technology, 2 281-288.

3. Afonso, P. C., Corrêa, P. C., Pinto, F. A. C. \& SAMPAIO, C. P. 2003 Shrinkage Evaluation of Five Different Varieties of Coffee. Biosystems Engineering, 86.

4. Alves, G., Borém, F., Isquierdo, E., Siqueira, V., Cirillo, M. \& Pinto, A. 2017. Physiological and sensorial quality of Arabica coffee subjected to different temperatures and drying airflows Acta Scientiarum, 39, 225-233.

5. AOAC 2007. Moisture determination. Official Methods of Analysis, 18th ed. AOAC International.

6. Bicho, N. C., Lidon, F. C., Ramalho, J. C. \& Leitão, A. E. 2013. Quality assessment of Arabica and Robusta green and roasted coffees - A review. J. Food Agric. ., 25 945-950.

7. Chandrasekar, V. \& Viswanathan, R. 1999. Physical and Thermal Properties of Co!ee. J. Agric. Engng Res. , 73, 227-234.

8. Coradi, P., Borém, F., Saath, R. \& Marques, E. 2007. Effect of drying and storage conditions on the quality of natural and washed coffee. Coffee Science, 2, 38-47.

9. Eke, C. N. U., Asoegwu, S. N. \& Nwandikom, G. I. 2007. Physical properties of jackbean (Canavalia ensiformis). . Agricultural Engineering International, 9, 1-11.

10. El Fawal, Y. A., Tawfik, M. A. \& El Shal, A. M. 2009. Study on Physical and Engineering Properties for Grains of Some Field Crops. Misr J. Ag. Eng., 26, 1933- 1951.

11. Farah, A., Monteiro, M., Calado, V., Franca, A. \& Trugo, L. 2006. Correlation between cup quality and chemical attributes of Brazilian coffee. Food Chemistry, 98, 373-380.

12. ICO 2018. Coffee Statistics. International Coffee Organization.

13. Isleten, M. \& Karagul-Yuceer, Y. 2006. Effects of Dried Dairy Ingredients on Physical and Sensory Properties of Nonfat Yogurt. J. Dairy Sci. , 89, 2865-2872.

14. Ismail, I., Anuar, M. S. \& Shamsudin, R. 2014. Physical Properties of Liberica Berries and Beans. Pertanika J. Sci. \& Technol. , 2265 - 79.

15. ISO. 1995. Green and roasted coffee - Determination of free-flow bulk density of whole beans (Routine method) [Online]. Available: https://www.iso.org/obp/ui/\#iso:std:iso:6669:ed-1:v1:en [Accessed].

16. Koskei, K., Patrick, M. \& Simon, M. 2015. Effects of coffee processing technologies on physicochemical properties and sensory qualities of coffee. African Journal of Food Science, 9, 230-236.

17. Lima, R., Oliveira, P., Borém, F., Isquierdo, E., Giomo, G. \& Cardoso, R. 2013. Physiological Aspects of Coffee Beans, Processed and Dried Through Different Methods, Associated with Sensory Quality. Coffee Science, 8, 203 - 211.

18. Mohsenin, N. N. 1986. Physical properties of plant and animal materials, New York, Gorden and Breach Science Publisher.

19. Niveditha, V. R., Sridhar, K. R. \& Balasubramanian, D. 2013. Physical and mechanical properties of seeds and kernels of Canavalia of coastal sand dunes. International Food Research Journal 20, 15471554 
20. Oliveira, A., Corrêa, P., Reis, E. \& De Oliveira, G. 2015. Comparative study of the physical and chemical characteristics of coffee and sensorial analysis by principal components. Food Anal. Methods 8, 1303-1314.

21. Olukunle, O. J. \& Akinnnuli, B. O. 2012. Investigating Some Engineering Properties of Coffee Seeds and Beans. Journal of Emerging Trends in Engineering and Applied Sciences 3, 743-747

22. Pittia, P., Nicoli, M. C. \& Sacchetti, G. 2007. Effect of moisture and water activity on textural properties of row and roasted coffee beans. Journal of Texture Studies., 38, 116-134.

23. Scott. 2015. Coffee Grades: How Coffee Is Sorted By Size [Online]. DRIFTAWAY. Available: https://driftaway.coffee/coffee-grades/ [Accessed December 12 2018].

24. Severa, L., Buchar, J. \& Nedomová, S. 2013. Shape and Size Varaibility of Roasted Arabica Coffee Beans. International Journal of Food Properties, 15, 426-437.

25. Sualeh, A. \& Mekonnen, N. 2015. Manual for Coffee Quality Laboratory. Ethiopian Institute of Agricultural Research, ISBN: $978999446605410-8$

26. Taser, O. F., Altuntas, E. \& Ozgoz, E. 2005. Physical properties of Hungarian and common vetch seeds. Journal of Applied Science 5, 323-326.

27. Taveria, J., Borem, F., Da Rosa, S., Oliveira, P., Giomo, G., Isquierdo, E. \& Fortunato, V. 2015. Postharvest effects on beverage quality and physiological performance of coffee beans. African Journal of Agricultural Research, 10, 1457-1466.

28. Tsegaye, B., Mohammed, A. \& Getachew, E. 2014. Impact of Sun Drying Methods and Layer Thickness on the Quality of Highland Arabica Coffee Varieties at Limmu, Southwestern Ethiopia. Journal of Horticulture, 1.

29. Vishwakarma, R. K., Shivhare, U. S. \& Nanda, S. K. 2012. Physical properties of guar seeds. . Food and Bioprocess Technology, 5, 1364-1371.

30. Wilson, M. 2018. Why does Density Matter and What affects the Density of Coffee? [Online]. Asia: Tourch Coffee Company. Available: https://www.torchcoffee.asia/blog-1/2018/7/9/why-does-densitymatter-and-what-affects-the-density-of-coffee [Accessed December 28 2018]. 